\title{
Chemical constituents and evaluation of the toxic and antioxidant activities of Averrhoa carambola leaves
}

\author{
Henrique H. Moresco, Gustavo S. Queiroz, Moacir G. Pizzolatti, \\ Inês M. C. Brighente*
}

Laboratório de Química de Produtos Naturais, Departamento de Química, Universidade Federal de Santa Catarina, Brasil.

\begin{abstract}
The liquid-liquid partitioning of a crude hydroalcoholic extract of Averrhoa carambola L., Oxalidaceae, leaves led to the isolation of a sterol and three flavone $C$-glycosides. From the $n$-hexane fraction $\beta$-sitosterol was isolated and from the ethyl acetate fraction apigenin-6-C- $\beta$-L-fucopyranoside (1) and apigenin$6-C$-(2"- $O-\alpha$-L-rhamnopyranosyl)- $\beta$-L-fucopyranoside (2) were obtained. Apigenin$6-C$-(2"- $O$ - $\alpha$-L-rhamnopyranosyl)- $\beta$-D-glucopyranoside (3) was isolated from the $n$-butanol fraction. Compound $\mathbf{3}$ is new, while $\mathbf{1}$ and $\mathbf{2}$ have been previously isolated from A. carambola. The antioxidant activity was measured using the DPPH radical scavenging assay and reducing power of iron (III) to iron (II) ions. The ethyl acetate and $n$-butanol fractions showed the most antioxidant activity. As evaluated by ability of the sample to scavenge DPPH the IC50 values were 90.92 and $124.48 \mu \mathrm{g}$ / $\mathrm{mL}$, respectively. In the assay of reducing power these fractions presented 135.64 and 125.12 of ascorbic acid equivalents, respectively. The antioxidant activity exhibited a significant relationship with the phenolic content $\left(r^{2}=0.997\right)$, but a poor relationship with the flavonoids content $\left(\mathrm{r}^{2}=0.424\right)$. The $n$-hexane fraction was the only fraction to present good toxicity using A. salina with LC50 $800.2 \mu \mathrm{g} / \mathrm{mL}$.
\end{abstract}

Revista Brasileira de Farmacognosia Brazilian Journal of Pharmacognosy 22(2): 319-324, Mar./Apr. 2012

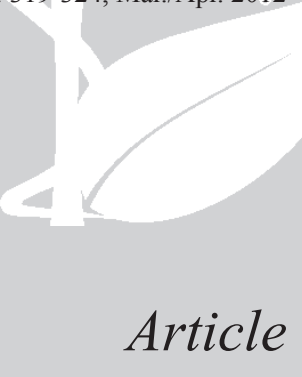

Article

Received 15 Apr 2011

Accepted 20 Sep 2011

Available online 29 Nov 2011

Keywords:

antioxidants

Artemia salina

Averrhoa carambola

C-glycosyl flavones

ISSN 0102-695X http://dx.doi.org/10.1590/S0102695X2011005000217

\section{Introduction}

The family Oxalidaceae comprises more than 900 species belonging to seven genera, namely, Oxalis, Biophytum, Sarcotheca, Dapania, Eichleria, Hypseocharis, and Averrhoa. The genus Averrhoa includes two of Oxalidaceae species, A. bilimbi and A. carambola (Zonlefer, 1994). Averrhoa carambola L., commonly known as star fruit or carambola, is a tree originally from Asia which has become acclimatized in many tropical countries, including Brazil. This plant is a small bush that can grow to 4-6 $\mathrm{m}$ in height (Pio Corrêa, 1926-1975; Panizza, 1998).

The leaves and fruits of $A$. carambola have been used in folk medicine as an appetite stimulant, a diuretic, an antidiarrheal, and a febrifugal agent, as well as in the treatment of eczemas (Pio Corrêa, 1984). Also, decoction of the leaves has been used in diabetes treatment (Provasi et al., 2001). Previous investigations on A. carambola have revealed the presence of steroids and triterpenes (Ranganayaki et al., 1980; Tadros \& Sleen, 2004), cyanidin glycosides (Gunasegaran, 1992), O-glycosyl flavonoids (Tiwari et al., 1979), and C-glycosyl flavones (Araho et al., 2005).

The species A. carambola presents hypoglycemic (Chau et al., 2004a; Ferreira et al., 2008), hypocholesterolemic (Chau et al., 2004b), antimicrobial (Hsu et al., 2007), antioxidant (Shui \& Leong, 2006), and anti-inflammatory (Cabrini et al., 2011) effects. An alcoholic extract of the stems of $A$. carambola has been shown to exhibit selective activity against brain tumor cells while that of the leaves was effective against liver carcinoma cells (Tadros \& Sleem, 2004). The aqueous leaf extract of $A$. carambola depresses atrial inotropism in the guinea pig (Vasconcelos et al., 2008).

In this paper we describe the isolation of one sterol and three glycosyl flavones from the leaves of $A$. carambola. A further aim of this study was to test the crude hydroalcoholic extract and $n$-hexane, ethyl acetate and $n$-butanol fractions in order to determine their toxicity towards Artemia salina and investigate their antioxidant activity using DPPH free radical scavenging and reducing potential assays.

\section{Materials and Methods}

\section{General procedures}

Column chromatography was performed over silica gel 230-400 mesh (Merck).Thin-Layer 
chromatography (TLC) was performed on a precoated silica gel type 60 plates (Merck), spots were located by spraying with ferric chloride. The IR spectrum was recorded on a Perkin Elmer FTIR 16 PC spectrophotometer; NMR spectra were recorded on a Varian AS-400 spectrometer using TMS as internal standard. The absorbance of the assays were measured (each measurement was repeated three-times) in a Hitachi UV-Vis U 3000 spectrophotometer (Tokyo, Japan). Artemia salina were obtained from dehydrated eggs purchased in a specialized store.

\section{Plant material}

The leaves of Averrhoa carambola L., Oxalidaceae, were collected in Santo Amaro da Imperatriz-SC (10 $0^{\circ} 53^{\prime} 57.55^{\prime} \mathrm{S}, 37^{\circ} 07^{\prime} 14.30^{\prime} \mathrm{W}$, altitude $10 \mathrm{~m}$ ) from a healthy and agrotoxic-free plant. Botanical identification was performed by Dr. Daniel de Barcellos Falkenberg. A voucher specimen (FLOR 24.144) has been deposited in the Herbarium FLOR, Universidade Federal de Santa Catarina, Santa Catarina, Brazil.

\section{Extraction and isolation}

The air-dried leaves of $A$. carambola $(281.0 \mathrm{~g})$ were extracted with $80 \%$ ethanol at room temperature for fifteen days. The solvent was removed by rotatory evaporation $\left(<55^{\circ} \mathrm{C}\right)$. The crude hydroalcoholic extract (41.3 g) was resuspended in EtOH: $\mathrm{H}_{2} \mathrm{O} 20: 80 \mathrm{v} / \mathrm{v}$ and partitioned with $n$-hexane, ethyl acetate (EtOAc) and $n$-butanol (n-BuOH) yielding the $n$-hexane (6.23\%), EtOAc $(16.70 \%)$ and $n-\mathrm{BuOH}(24.70 \%)$ fractions, respectively.

The $n$-hexane fraction $(2.6 \mathrm{~g})$ was subjected to silica gel chromatographic column, using $n$-hexane, EtOAc and $\mathrm{EtOH}$ in mixtures of increasing polarity. Recrystallization from $n$-hexane of one fraction resulted in a compound obtained as white crystals (hex/ EtOAc 90\%; $15 \mathrm{mg}$; mp $120.1-121.5{ }^{\circ} \mathrm{C}$ ), identified as $\beta$-sitosterol (Garg \& Nes, 1984; De-Eknamkul \& Potduang, 2003).

The EtOAc fraction (6.9 g) chromatographed on silica gel using EtOAc/EtOH mixtures with increasing polarity yielded 36 fractions $(100 \mathrm{~mL})$, which were combined in sub-fractions according to TLC analysis. The sub-fraction 6-8 (EtOAc/EtOH 98\%) analyzed by TLC ( $\mathrm{R}_{\mathrm{f}}$ 0.65, EtOAc/MeOH 90\%), yielded a yellow amorphous powder, and after successive recristallizations under methanol yield $150 \mathrm{mg}$ of apigenin-6-C- $\beta$-Lfucopyranoside (1). The sub-fraction 10-13 (EtOAc/EtOH $95 \%)$ was analyzed by TLC $\left(\mathrm{R}_{\mathrm{f}} 0.37\right.$, EtOAc/MeOH $90 \%$ ), yielded a yellow solid. After recristallizations under methanol yielded $200 \mathrm{mg}$ of apigenin-6-C-(2"- $O-\alpha-\mathrm{L}-$ rhamnopyranosyl)- $\beta$-L-fucopyranoside (2). Identification of these flavonoids were carried out by interpretation of their spectral data as well as by comparison with data reported in the literature (Cazarolli et al., 2009b; Suzuki et al., 2003; Araho et al., 2005). Analysis of the $n-\mathrm{BuOH}$ fraction $(10.2 \mathrm{~g})$ followed the same chromatographic procedure. Sub-fraction 11-13 (EtOAc/EtOH 70\%) after observations on TLC $\left(\mathrm{R}_{\mathrm{f}} 0.45\right.$, EtOAc/MeOH $\left.80 \%\right)$ led to the isolation of $8.6 \mathrm{mg}$ of apigenin-6-C-(-2"- $O-\alpha-\mathrm{L}-$ rhamnopyranosyl)- $\beta$-D-glucopyranoside (3) as a white solid.

Apigenin-6-C-(-2"-O- $\alpha$-L-rhamnopyranosyl)- $\beta$-Dglucopyranoside (3): mp 253-256 ${ }^{\circ} \mathrm{C}$; IR bands (KBr): 3377, 2909, 1607, 1648, 1453, 1349, 1248, 1183, 1077, 835. NMR ${ }^{1} \mathrm{H}$ (400 MHz, DMSO-d6): 6.97 (s, H-3), 6.90 (s, H-8), 7.96 (d; 8.8 Hz, H-2', 6'), 6.94 (d; 8.8 Hz, H-3', 5'), 5.19 (d; 9.9 Hz, H-1”), 4.55 (m, H-2”), 3.83 (m, H-3"), 3.61 (m, H-4"), 3.50 (m, H-5”), 4.35 (m, H-6”), 5.11 (sl, H-1"'), 3.59 (m, H-2"), 3.23 (m, H-3"'), 2.95 (m, H-4"”), 2.49 (m, H-5"'), 1.09 (d; 6.4 Hz, H-6"'). NMR ${ }^{13} \mathrm{C}(100$ MHz, DMSO-d6): 164.86 (C-2), 103.81 (C-3), 182.84 (C-4), 162.05 (C-5), 111.86 (C-6), 163.64 (C-7), 95.32 (C-8), 159.92 (C-9), 102.82 (C-10), 121.59 (C-1'), 129.32 (C-2' and C-6'), 116.72 (C-3' and C-5'), 157.08 (C-4'), 73.72 (C-1”), 75.71 (C-2”), 76.38 (C-3”), 70.53 (C-4”), 78.06 (C-5"), 61.47 (C-6”), 105.69 (C-1"”), 74.56 (C-2"”), 74.15 (C-3"”), 72.57 (C-4"”), 68.24 (C-5"”), 17.64 (C-6"”). The NMR $\mathrm{H}^{1}$ and $\mathrm{C}^{13}$ data are in agreement with the literature data (Rayyan et al., 2005).

\section{Biological activity}

The crude hydroalcoholic extract and the fractions of the liquid-liquid partition ( $n$-hexane, EtOAc and $n-\mathrm{BuOH})$ were subjected to different assays. The results were subjected to analysis of variance (ANOVA) and Fisher's test for multiple comparisons, setting $p<0.05$ for statistical significance indices.

\section{Determination of total phenolic}

The amount of total phenolics was determined using the Folin-Ciocalteu method (Gutfinger, 1981), with modifications. In this method, the reaction mixture was composed of $0.5 \mathrm{~mL}$ of extract $(1.0 \mathrm{mg} / \mathrm{mL}), 5.0 \mathrm{~mL}$ of distilled water, and $0.5 \mathrm{~mL}$ of the Folin-Ciocalteu reagent. After a period of $3 \mathrm{~min}, 1.0 \mathrm{~mL}$ of saturated sodium carbonate solution was added. These mixtures were shaken and allowed to stand for $1 \mathrm{~h}$. The absorbance was measured at $725 \mathrm{~nm}$. A calibration curve of gallic acid was prepared $\left(y=5.51 x+1.77 ; r^{2}=0.999\right)$, and the results were expressed as gallic acid (GA) equivalents (mg gallic acid/g dry extract). 
<smiles></smiles>

$1 \mathrm{R}_{1}=\mathrm{H}$

$2 \mathrm{R}_{1}=$ Rham

\section{Determination of total flavonoid content}

The total flavonoid content was determined spectrophotometrically according to Lamaison and Carnat (Quettier-Deleu et al., 2000) with modifications. Briefly, $0.5 \mathrm{~mL}$ of $2 \%$ aluminum chloride $\left(\mathrm{AlCl}_{3}\right)$ in ethanol was mixed with the same volume of vegetal extracts $(1.0 \mathrm{mg} /$ $\mathrm{mL}$ ). Absorption readings at $415 \mathrm{~nm}$ were taken after 1 $\mathrm{h}$ against a blank (ethanol). The total flavonoid content was determined using a standard curve with quercetin $\left(y=8.776 x+0.869 ; r^{2}=0.999\right)$. The mean of three readings was used and expressed as quercetin (QE) equivalents (mg quercetin/g of dry extract).

\section{$D P P H$ radical scavenging assay}

The free radical scavenging activity of the vegetal sample was measured using the method described by Brand Williams et al. (1995) with some modifications. One milliliter of the ethanol extracts of the plants and compounds $(5-200 \mu \mathrm{g} / \mathrm{mL})$ was added to $2 \mathrm{~mL}$ of a solution of DPPH radicals in methanol $(0.004 \%)$. The mixture was shaken vigorously and allowed to stand for 30 min at room temperature. The absorbance $\left(\mathrm{Abs}_{\text {sample }}\right)$ of the resulting solution was measured at $517 \mathrm{~nm}$ and converted into percentage of antioxidant activity (AA) using the following formula: $\mathrm{AA} \%=100-\left\{\left[\left(\mathrm{Abs}_{\text {sample }}-\mathrm{Abs}_{\text {blank }}\right) \times 100\right] /\right.$ $\left.\mathrm{Abs}_{\text {control }}\right\}$. A ethanol $(2.0 \mathrm{~mL})$ and plant extract/compound $(1.0 \mathrm{~mL})$ solution was used as the blank $\left(\mathrm{Abs}_{\text {blank }}\right)$. A DPPH $(2.0 \mathrm{~mL})$ and ethanol $(1.0 \mathrm{~mL})$ solution was used as the control $\left(\mathrm{Abs}_{\text {control }}\right)$. Ascorbic and gallic acids were used as standards. The radical scavenger activity was expressed in terms of the amount of antioxidants necessary to decrease the initial DPPH absorbance by $50 \%$ (IC50). The IC50 value for each sample was determined graphically by plotting the percentage disappearance of DPPH as a function of the sample concentration.

\section{Determination of reducing power}

This assay is based on the method of Price \&

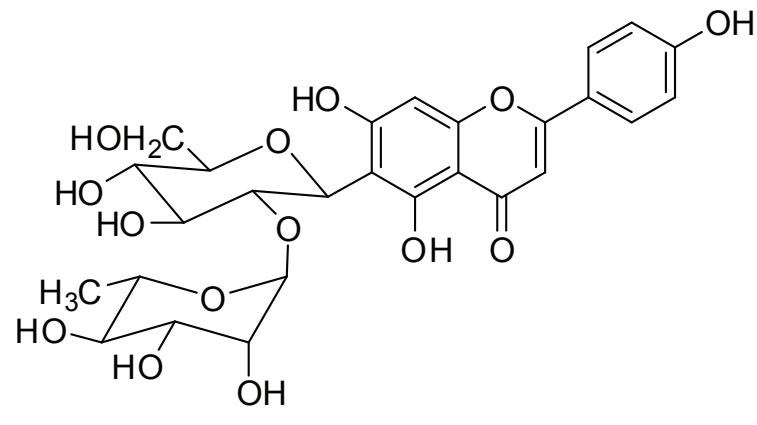

3

Butler, proposed by Waterman \& Mole (1994), with modifications. $100 \mathrm{~mL}$ of test solutions (crude extracts and fractions, diluted in methanol at a concentration of $1000 \mathrm{ppm}$ ) were added to $8.5 \mathrm{~mL}$ of deionized water. It was then added $1.0 \mathrm{~mL}$ of $0.1 \mathrm{M} \mathrm{FeCl}_{3}$, and after $3 \mathrm{~min}$, $1.0 \mathrm{~mL}$ of $0.08 \mathrm{M}$ potassium ferricyanide. After $15 \mathrm{~min}$, the absorbance was measured at $720 \mathrm{~nm}$. For the blank, was used a solution prepared as above without the addition of the sample. The reducing power was determined using a standard curve with ascorbic acid $(y=0.0015 x+0.124$; $\left.r^{2}=0.999\right)$. The results were expressed as ascorbic acid (AA) equivalents (mg ascorbic acid/ g dry extract).

\section{Toxicity in Artemia salina}

The extracts, fractions and pure isolated compounds were evaluated in a test for toxic activity against larvae of Artemia salina (Meyer et al., 1982), with minor modifications. Toxicities of compounds were tested at 10-1000 ppm in $1 \mathrm{~mL}$ sea-water solutions with $1 \%$ DMSO (v/v). Ten, one-day nauplii were used in each test and survivors counted after $24 \mathrm{~h}$. Three replications were used for each concentration. A parallel series of tests with the standard potassium dichromate solution (LC50 20-40 ppm) and the blank control were always conduced. After $24 \mathrm{~h}$ of exposure, the results were expressed as LC50 value, concentration able to kill $50 \%$ of the larvae.

\section{Results and Discussion}

The liquid-liquid partitioning of a crude hydroalcoholic extract of $A$. carambola leaves resulted in the isolation of $\beta$-sitosterol (Garg \& Nes, 1984; De-Eknamkul \& Potduang, 2003) from the $n$-hexane fraction and two $C$-glycosyl flavones, apigenin-6- $C$ $\beta$-L-fucopyranoside (1) and apigenin-6-C- $(2$ "- $O-\alpha-\mathrm{L}-$ rhamnopyranosyl)- $\beta$-L-fucopyranoside (2), from the EtOAc fraction. These compounds had previously been isolated from $A$. carambola leaves (Ranganayaki et al., 1980; Araho et al., 2005). Recently, studies have shown that these flavones reduce blood glucose levels in diabetic rats, stimulate insulin secretion and potentiate 
glucose-induced insulin secretion in hyperglycemic rats. In addition, these flavonoids can stimulate glucose uptake in rat soleus muscle through the involvement of the well-known mechanism of insulin signal transduction (Cazarolli et al., 2009a,b). Apigenin-6-C-(-2"-O- $\alpha-\mathrm{L}-$ rhamnopyranosyl)- $\beta$-D-glucopyranoside (3) was isolated from the $n-\mathrm{BuOH}$ fraction and is reported for the first time in A. carambola. Compound $\mathbf{3}$ has previously been found in Oxalis triangularis of the Oxalidaceae family (Rayyan et al., 2005). The low yield of this compound prevented subsequent biological studies.

The crude extract of the leaves of Averrhoa carambola, and the fractions obtained from the liquidliquid partitioning, were evaluated for antioxidant activity. The antioxidant activity in plants is associated with phenolic compounds, mainly flavonoids. According to Table 1, the highest phenolic contents were found in the EtOAc and $n$-BuOH fractions. In these fractions the most accentuated antioxidant activity was observed, as evaluated through of the ability of the extract or fraction to scavenge DPPH and to reduce iron(III) to iron(II) ions. This suggests that the high antioxidant activity of the more polar fractions is probably due to the substances with a hydroxyl group, capable of donating a hydrogen radical to the oxidant molecule (Mensor et al., 2001).

The flavonoids are a class of vegetal secondary metabolites of phenolic nature, which have remarkable antioxidant properties. According to the results shown in Table 1, it can be seen that the highest concentration of flavonoids is present in the EtOAc fraction, with $35.25 \mathrm{mg} \mathrm{QE} / \mathrm{g}$ dry fraction. This result is in agreement with the data obtained in the phytochemical analysis of the fraction which yielded flavonoids $\mathbf{1}$ and 2 . The low activity observed for the $n$ - $\mathrm{BuOH}$ fraction was probably due to the low concentration of flavonoid 3. A direct correlation was observed between the ability to capture the DPPH with the phenolic content, with a correlation coefficient of $r^{2}=0.997$. This good correlation confirms the data presented in several other studies, which have shown that the antioxidant capacity is strongly correlated with the content of phenolic compounds (Kaur \& Kapoor, 2002; Thaipong et al., 2005; Abdille et al., 2005; Makris et al., 2007). However, no relationship is maintained when correlating the ability to capture the DPPH with the amount of flavonoids in the extract and fractions of A. carambola $\left(\mathrm{r}^{2}=0.424\right)$. Flavonoids $\mathbf{1 - 3}$ were also tested through observing the capture of free radicals and these compounds showed IC50 values greater than $200 \mu \mathrm{g} /$ $\mathrm{mL}$, considered high values for isolated compounds. So, it shows that these flavonoids are not responsible for the antioxidant activity of the EtOAc and $n-\mathrm{BuOH}$ fractions.

Determination of the toxicity to Artemia salina has been used efficiently to analyze the biological potential of plant extracts (Colegate \& Molyneux, 1993). Several natural compounds, particularly substances with antitumoral, antimicrobial, insecticidal and antitrypanosomicidal activity, have been tested through these bioassays, showing a significant correlation (Meyer et al., 1982; McLaughlin et al., 1991; Alves et al., 2000). According to Meyer et al., (1982) who classified crude extracts and pure substances as toxic (LC50 value $<1000 \mu \mathrm{g} / \mathrm{mL}$ ) or non-toxic (LC50 value $>1000 \mu \mathrm{g} / \mathrm{mL}$ ), $n$-hexane was the only fraction to present good toxicity against $A$. salina (LC50 $800.2 \mu \mathrm{g} / \mathrm{mL}$ ). This activity can be explained by the presence of $\beta$-sitosterol the activity of which is described in the literature, with an LC50 value of $79 \mu \mathrm{g} / \mathrm{mL}$ (Adoum, 2009). Toxic activity was observed for compounds $\mathbf{1}$ and $\mathbf{2}$ with LC50 values of $134.3 \mu \mathrm{g} /$ $\mathrm{mL}$ and $95.5 \mu \mathrm{g} / \mathrm{mL}$, respectively. However, no activity was observed for the EtOAc and $n-\mathrm{BuOH}$ fractions. This is probably due to the low concentration of compounds $\mathbf{1}$, $\mathbf{2}$ and $\mathbf{3}$ in these fractions.

\section{Conclusions}

This paper reports on a phytochemical investigation involving Averrhoa carambola leaves and the evaluation of toxicity and antioxidant effect. The glycosyl flavone $\mathbf{3}$ is reported for the first time in $A$. carambola. The compounds isolated from $A$. carambola showed low antioxidant activity but high toxicity against Artemia salina. This indicates that the toxic activity displayed by the isolated compounds is not associated with the antioxidant activity observed for the extracts.

Table 1. Antioxidant activity of crude extract and fractions of Averrhoa carambola.

\begin{tabular}{lcccc}
\hline \multicolumn{1}{c}{ Extract/Fraction } & $\begin{array}{c}\text { Phenolics } \\
(\mathrm{mgGA}) / \mathrm{g}\end{array}$ & $\begin{array}{c}\text { Flavonoids } \\
\mathrm{mgQE} / \mathrm{g}\end{array}$ & $\begin{array}{c}\text { Reducing potential } \\
\mathrm{mgAA} / \mathrm{g}\end{array}$ & $\begin{array}{c}\mathrm{DPPH} \\
\mathrm{IC} 50 \mu \mathrm{g} / \mathrm{mL}\end{array}$ \\
\hline Crude extract & $33.39+0.35$ & $14.28+1.31^{(*)}$ & $98.02+0.23$ & $212.59+0.30$ \\
$n$-hexane & $29.44+0.36$ & $26.70+0.74$ & $86.22+1.52$ & $223.67+0.98$ \\
EtOAc & $79.07+0.63$ & $35.25+0.05$ & $135.64+1.63$ & $90.92+0.10$ \\
$n$-BuOH & $59.66+1.00$ & $14.23+0.23^{(*)}$ & $125.12+1.63$ & $124.48+1.21$ \\
Ascorbic acid & - & - & - & $8.4+0.26$ \\
Gallic acid & - & - & - & $2.6+0.01$ \\
\hline
\end{tabular}

All means, except those marked by ${ }^{(*)}$, showed significant differences in the Fisher test $(p<0.05)$. 


\section{Acknowledgments}

The authors are grateful to Conselho Nacional de Desenvolvimento Cientifico e Tecnológico for financial aid and to Prof. Dr. Daniel de Barcellos Falkenberg for the identification of plant material.

\section{References}

Abdille MDH, Singh RP, Jayaprakasha GK, Jena BS 2005. Antioxidant activity of the extracts from Dillenia indica fruits. Food Chem 90: 891-896.

Adoum OA 2009. Absolute configuration of components isolated from the root of Ximenia americana Linn. Int J Chem 19: 67-72.

Alves TMD, Silva AF, Brandão M, Grandi TSM, Smânia EFA, Smânia A, Zani CL 2000. Biological screening of Brazilian medicinal plants. Mem Inst Oswaldo Cruz 95: 367-373.

Araho D, Miyakoshi M, Chou W, Kambara T, Mizutani K, Ikeda T 2005. A new flavone $C$-glycoside from the leaves of Averrhoa carambola. Nat Med 59: 113116.

Brand Williams W, Cuvelier ME, Berset C 1995. Use of a free-radical method to evaluate antioxidant activity. Food Sci Technol-Lebens Wissens Technol 28: 25-30.

Cabrini DA, Moresco HH, Imazu P, Silva CD, Pietrovski EF, Mendes DAGB, Prudente AS, Pizzolatti MG, Brighente IMC, Otuki MF 2011. Analysis of the potential topical anti-inflammatory activity of Averrhoa carambola L. in mice. Evid-Based Compl Alt 2011: doi:10.1093/ecam/neq026.

Cazarolli LH, Folador P, Moresco HH, Brighente IMC, Pizzolatti MG, Silva FRMB 2009a. Mechanism of action of the stimulatory effect of apigenin-6C-(2"- $O$ - $\alpha$-L-rhamnopyranosyl)- $\beta$-fucopyranoside on 14C-glucose uptake. Chem-Biol Interact 179: 407-412.

Cazarolli LH, Folador P, Moresco HH, Brighente IMC, Pizzolatti MG, Silva FRMB 2009b. Stimulatory effect of apigenin-6-C- $\beta$-L-fucopyranoside on insulin secretion and glycogen synthesis. Eur $J$ Med Chem 44: 4668-4673.

Chau C, Chen C, Lin C 2004a. Insoluble fiber-rich fractions derived from Averrhoa carambola: hypoglycemic effects determined by in vitro methods. Lebensm Wiss Technol 37: 331-335.

Chau C, Chen C, Wang Y 2004b. Effects of a novel pomace fiber on lipid and cholesterol metabolism in the hamster. Nutr Res 24: 337-345.

Colegate SM, Molyneux RJ 1993. Bioactive Natural Products: Detection, Isolation and Structural Determination. London: CRC Press.

De-Eknamkul W, Potduang B 2003. Biosynthesis of sitosterol and stigmasterol in Croton sublyratus proceeds via a mixed origin of isoprene units. Phytochemistry 62: 389-398.

Ferreira EB, Fernandes LC, Galende SB, Cortez DAG, Bazotte RB 2008. Hypoglycemic effect of the hydroalcoholic extract of leaves of Averrhoa carambola L. (Oxalidaceae). Rev Bras Farmacogn 18: 339-343.

Garg VK, Nes WR 1984. Codisterol and other 5-sterols in the seeds of Cucurbita maxima. Phytochemistry 23: 2925-2929.

Gunasegaran R 1992. Flavonoids and anthocyanins of three Oxalidaceae. Fitoterapia 63: 89-90.

Gutfinger T 1981. Polyphenols in olive oils. J Am Oil Chem Soc 58: 966-996.

Hsu P-K, Chien P-J, Chau C-F 2007. An exploitation of the antimicrobial potential of a fruit insoluble fibre by micronization. Eur Food Res Technol 225: 199204.

Kaur C, Kapoor HC 2002. Anti-oxidant activity and total phenolic content of some Asian vegetables. Int $J$ Food Sc Tech 37: 153-161.

Makris DP, Boskou G, Andrikopoulos NK 2007. Polyphenolic content and in vitro antioxidant characteristics of wine industry and other agri-food solid waste extracts. J Food Composit Anal 20: 125-132.

McLaughlin JL, Chang CJ, Smith DL 1991. "Bench top" bioassay for the discovery of bioactive natural products: an update. In: Rahman AU (Ed). Studies in Natural Products Chemistry Amsterdam: Elsevier, p. 383-409.

Mensor LL, Menezes FS, Leitão GG, Reis AS, dos Santos TC, Coube CS, Leitão SG 2001. Screnning of Brazilian plant extracts for antioxidant activity by the use of DPPH free radical method. Phytother Res 15: 127-130.

Meyer BN, Ferrigini NR, Putnan JE, Jacobsen LB, Nichols DE, Mclaughlin JL 1982. Brine shrimp: a convenient general bioassay for active plant constituents. Planta Med 45: 31-34.

Panizza S 1998. Plantas que Curam (Cheiro de Mato). São Paulo: IBRASA.

Pio Corrêa M 1926-1975. Dicionário de Plantas Úteis do Brasil e das Exóticas Cultivadas. Rio de Janeiro: Ministério da Agricultura.

Pio Corrêa M 1984. Dicionário das plantas úteis do Brasil e das exóticas cultivadas. Rio de Janeiro: Instituto de Desenvolvimento Florestal.

Provasi M, Oliveira CE, Martinho MC, Pessini LG, Bazotte RB, Cortez DAG 2001. Avaliação da toxicidade e do potencial anti-hiperglicemiante da Averrhoa carambola L. (Oxalidaceae). Acta Scientiarum 23: 665-669.

Quettier-Deleu C, Gressier B, Vasseur J, Dine T, Brunet C, 
Luyckx MC, Cazin JC, Bailleul F, Trotin F 2000. Phenolic compounds and antioxidant activities of buckwheat (Fagopyrum esculentum Moench) hulls and flour. J Ethnopharmacol 72: 35-42.

Ranganayaki S, Singh R, Singh AK 1980. The chemical examination of the bark of Averrhoa carambola. Physical Sci 50: 61-63.

Rayyan S, Fossen T, Andersen OM 2005. Flavone C-glycosides from leaves of Oxalis triangularis. $J$ Agr Food Chem 53: 10057-10060.

Shui G, Leong LP 2006. Residue from star fruit as valuable source for functional food ingredients and antioxidant nutraceuticals. Food Chem 97: 277284.

Suzuki R, Okada Y, Okuyama T 2003. A new flavone $C$-glycoside from the style of Zea mays L. with glycation inhibitory activity. Chem Pharm Bull 51: 1186-1188.

Tadros SH, Sleem AA 2004. Pharmacognostical and biological study of the stem and leaf of Averrhoa carambola L. grown in Egypt. Bulletin of the Faculty of Pharmacy (Cairo University) 42: 225 246.

Thaipong K, Boonprakob U, Cisneros-Zevallos L, Byrne DH 2005. Hydrophilic and lipophilic antioxidant activities of guava fruits. SE Asian J Trop Med 36: 254-257.
Tiwari KP, Masood M, Minocha PK 1979. Chemical constituents of Gmelina phillipinensis, Adenocalymna nitida, Allamanda cathartica, Averrhoa carambola and Maba buxifolia. J Indian Chem Soc 56: 944-944.

Vasconcelos CML, Gondim ANS, Cruz JS, Mafra RA, Silva BA, Conde-Garcia EA 2008. Aqueous leaf extract of Averrhoa carambola L. (Oxalidaceae) reduces both the inotropic effect of BAY K 8644 on the guinea pig atrium and the calcium current on GH3 cells. Rev Bras Farmacogn 18: 539-543.

Zonlefer WB 1994. Guide to flowering plant families. Chapel Hill: University of North Carolina Press.

Waterman PG \& Mole S 1994. Analysis of phenolic plant metabolites. Blackwell Scientific Publications, Oxford, pp. 66-103.

\section{*Correspondence}

Inês M. C. Brighente

Laboratório de Química de Produtos Naturais, Departamento de Química, Universidade Federal de Santa Catarina, Campus Trindade, 88040-900 Florianópolis-SC, Brazil

ines@qmc.ufsc.br

Tel. + 554837216846

Fax: + 554837219711 